\title{
A comparative study of surface energy data from atomic force microscopy and from contact angle goniometry
}

\author{
Dimitrios A. Lamprou ${ }^{a}$, James R. Smith ${ }^{a}$, Thomas G. Nevell ${ }^{a}$, Eugen Barbu ${ }^{a}$, \\ Corinne Stone $^{\mathrm{b}}$, Colin R. Willis ${ }^{\mathrm{b}}$, John Tsibouklis ${ }^{\mathrm{a}, *}$
}

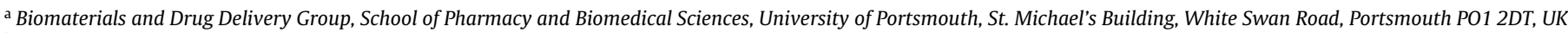

b Physical Sciences Department, Dstl Porton Down, Salisbury SP4 0JQ UK

\section{A R T I C L E I N F O}

\section{Article history:}

Received 30 November 2009

Received in revised form 11 February 2010

Accepted 12 March 2010

Available online 19 March 2010

\section{Keywords:}

Surface energy

Atomic force microscopy

Alkanethiols

Self-assembly

Goniometry

\begin{abstract}
A B S T R A C T
Forces of adhesion have been measured for interactions involving self-assembled monolayers or polymerfilm structures that had each been deposited onto a gold-coated glass substrate and a probing, gold-coated cantilever. The data have been fitted into mathematical models that allow the calculation of surface energy by considering the work done for the separation of the identically coated contacting surfaces. These values of surface energy are in close agreement with those from corresponding contact angle determinations, highlighting the potential usefulness of the technique for the study of surfaces at a resolution level approaching 1000 atoms. Comparative studies show that the employment of the atomic force microscopy technique may be preferable for the study of samples that are susceptible to penetration by liquids or for investigations under conditions that exceed the useful limits of conventional probing techniques involving liquids.
\end{abstract}

(C) 2010 Elsevier B.V. All rights reserved.

\section{Introduction}

Surface energy $\left(\gamma_{s}, \gamma_{l}\right.$; work required to generate unit surface area of a solid or liquid) provides a measure of the mutual affinity of interacting surfaces [1-3]. Direct determinations of $\gamma_{l}$ have enabled values of $\gamma_{s}$ to be obtained from measurements of contact angle $(\theta$, the internal angle of a tangent drawn at the boundary of a liquid in contact with a solid surface; contact angle goniometry, CAG) [4-6]. The values of $\theta$ for a plane surface reflect interfacial intermolecular attractive forces, with relatively weak attractions giving wide angles and strong attractions giving narrow angles or surface wetting $\left(\theta=0^{\circ}\right)$. It is generally accepted that $\gamma$ is the sum of apolar $(D)$ and polar $(P)$ contributions, Eq. (1):

$\gamma=\gamma^{D}+\gamma^{P}$

Good and van Oss treat the apolar contribution as arising from van der Waals forces (Lifshitz-van der Waals, $\gamma^{L W}$ ) and the polar contribution $\gamma^{A B}$ as the geometric mean of Lewis acid and base components $\gamma^{+}$and $\gamma^{-}$, Eq. (2) [7-9]:

$\gamma=\gamma^{L W}+\gamma^{A B}=\gamma^{L W}+2\left(\gamma^{+} \gamma^{-}\right)^{0.5}$

\footnotetext{
* Corresponding author. Tel.: +44 (0)23 9284 2131; fax: +44 (0)23 92843565. E-mail address: john.tsibouklis@port.ac.uk (J. Tsibouklis).
}

The contact angle is determined by the balance of forces acting at a liquid boundary on a solid surface, Eq. (3) (Owens-Wendt [10]) or (4):

$$
\begin{aligned}
& \left.\gamma_{l}(1+\cos \theta)=2\left[\gamma_{S}^{D} \gamma_{l}^{D}\right]^{0.5}+\left(\gamma_{S}^{P} \gamma_{l}^{P}\right)^{0.5}\right] \\
& \gamma_{l}(1+\cos \theta)=2\left[\left(\gamma_{S}^{L W} \gamma_{l}^{L W}\right)^{0.5}+\left(\gamma_{S}^{+} \gamma_{l}^{-}\right)^{0.5}+\left(\gamma_{S}^{-} \gamma_{l}^{+}\right)^{0.5}\right]
\end{aligned}
$$

Since for a wide range of liquids $\gamma_{l}$ and its components may be determined from measurements of surface and liquid interfacial tension [7], the solid surface energy components may be obtained from measurements of the contact angles of two or three liquids (commonly water, 1,2-ethanediol and diiodomethane), and hence $\gamma$ from Eq. (1) [10] or Eq. (2) [7,8]. Most liquid-solid interactions exhibit hysteresis according to whether the liquid is advancing over the surface or receding from it. This is due to surface roughness and/or heterogeneity and is most readily investigated by dynamic contact angle analysis (Wilhelmy plate) [11]. Better surface resolution of ca. $2.5 \mathrm{~mm}$, however, is obtained by the liquid drop method in which volumes of $1-5 \mu l$ are used $[7,8]$.

Force-of-adhesion measurements with the atomic force microscope (AFM) evaluate the affinity of the tip-surface of the probe cantilever for the substrate. The tip-surface force-of-adhesion $\left(F_{a d}\right)$ is obtained from measurements of "force $F$ against separation $x "$ as the sample $(S)$ in the medium $(M)$ is brought towards the tip $(T)$ and then withdrawn [12,13]. $F_{a d}$ may be related to the work of adhesion $\left(W_{a d}\right)$ by using either the Johnson-Kendall-Roberts (JKR) theory, which takes account only 
of attractive forces that act within the tip-substrate contact area $[12,13]$, or the Derjaguin-Muller-Toporov (DMT) theory, which allows in addition for the influence of long-range surface forces operating outside this area [12,14]. The DMT model is considered more appropriate for a hard material of low surface energy interacting with a sharp tip (low radius, $R$ ), whereas the application of the JKR theory is generally preferred for relatively soft materials with higher surface energies and for experiments utilising tips with relatively large radii [15]. The derived relationships are similar, Eq. (5) $[15,16]$ :

$F_{a d}=c \pi R W_{a d}=c \pi R\left(\gamma_{S M}+\gamma_{T M}-\gamma_{S T}\right)$

where $c=1.5$ and 2 , respectively, for JKR and DMT models, and $\gamma_{S M}$, $\gamma_{T M}$ and $\gamma_{S T}$ are the interfacial energies. If the tip and the sample consist of the same material then $\gamma_{S M}=\gamma_{T M}$ and $\gamma_{S T}=0$ [16] and it follows that:

$\gamma_{S M}=\gamma_{T M}=\frac{1}{2} W_{a d}=\frac{F_{a d}}{2 c \pi R}$

It has been found that $F_{a d}$ is lower when a liquid, with molecular functional groups similar to those on the material's surface, is interposed between tip and sample $[17,18]$. Further, the adhesive forces between tips and substrates that have both been modified with self-assembled monolayers (SAMs) terminated with $\mathrm{CH}_{3}, \mathrm{OH}$, and $\mathrm{CO}_{2} \mathrm{H}$ groups, measured in organic and aqueous solvents and under inert dry atmospheres $[19,20]$, correspond with the predictions of the JKR theory and correlate with surface energy values [21-23].

Many determinations using CAG have shown that the surface energy of a polymeric material depends upon the molecular structure of the surface layer; for example, $\mathrm{CH}_{3}$ groups possess lower surface energy than $\mathrm{CH}_{2}$ groups and covalently bound fluorine atoms considerably reduce the surface energy [7,24-27]. Amongst other attempts to establish the relationship between $F_{a d}$ and $\gamma$ [19,28-35], Awada et al. have reported the use of AFM to determine the surface energies of $\mathrm{CH}_{3}$ - and $\mathrm{OH}$-terminated SAMs on gold-coated tips and silicon wafers but the respective values for $\gamma_{s}$ of $8.5 \pm 1 \mathrm{~mJ} \mathrm{~m}^{-2}$ and $39 \pm 3 \mathrm{~mJ} \mathrm{~m}^{-2}$ were found to be appreciably smaller than those determined using CAG $\left(\mathrm{CH}_{3}: 22 \pm 2 \mathrm{~mJ} \mathrm{~m}^{-2}\right.$; $\mathrm{OH}: 73 \pm 2 \mathrm{~mJ} \mathrm{~m}^{-2}$ ) [25]. In the case of $\mathrm{OH}$, hydrogen bonding (short range, directional) between two solid surfaces in contact is likely to be less than between a liquid and a solid.

This work pursues the use of AFM as a high-resolution technique for the determination of surface energy, and compares data from this method with those from CAG. Surface energies have been evaluated from $F_{a d}$ data for SAMs formed from alkanethiols $\mathrm{HS}-\left(\mathrm{CH}_{2}\right)_{n}-\mathrm{X}\left(\mathrm{X}=\mathrm{OH}, \mathrm{CO}_{2} \mathrm{H}\right.$ and $\left.\mathrm{CH}_{3}\right)$ and $\mathrm{HS}-\left(\mathrm{CH}_{2}\right)_{2}\left(\mathrm{CF}_{2}\right)_{7} \mathrm{CF}_{3}$ that had each been deposited onto gold-coated silicon AFM tips and gold-coated glass substrates [36], and for plasmadeposited polymer coatings of 2-hydroxyethyl methacrylate (HEMA), 2-(dimethylamine)ethyl methacrylate (DMAEMA) and $1 \mathrm{H}, 1 \mathrm{H}, 2 \mathrm{H}, 2 \mathrm{H}$-perfluorodecyl acrylate (PFAC8), also on gold-coated substrates and AFM tips.

\section{Materials and methods}

\subsection{Surface preparation}

Gold-coated glass microscope slides (Au.1000.ALSI, Platypus Technologies, Madison, Wisconsin, USA, cut to $1.25 \mathrm{~cm} \times 1.25 \mathrm{~cm}$ ) and gold-coated AFM tips (silicon nitride V-shaped cantilevers and tips; NPG-20 'A' and ' $C$ '; nominal length $l_{\text {nom }}=115 \mu \mathrm{m}$ (' $A$ ' and ' $C$ '); width measured perpendicular to long axis $w_{\text {nom }}=25 \mu \mathrm{m}$ ' $A$ ', $17 \mu \mathrm{m}$ ' $\mathrm{C}$ '; resonant frequency $v_{\text {nom }}=57 \mathrm{kHz}$ (' $\mathrm{A}$ ' and ' $\mathrm{C}$ '); spring constant $k_{\text {nom }}=0.58 \mathrm{~N} \mathrm{~m}^{-1}$ 'A', $0.32 \mathrm{~N} \mathrm{~m}^{-1}$ ' $\mathrm{C}$ '; gold thickness $=60 \mathrm{~nm}$ on an adhesion layer of chromium $15 \mathrm{~nm}$; Veeco Instruments SAS, Dour- dan, France) were cleaned by immersion in Gold Surface Cleaning solution (Sigma-Aldrich, Poole, UK; $1 \mathrm{~h}, 15 \mathrm{~min}$, respectively) followed by rinsing (filtered water, Millipore, $16.5 \mathrm{M} \Omega \mathrm{cm}$ ) and drying (nitrogen). AFM " $F$ vs. $x$ " measurements and CAG have shown that this cleaning procedure allows the repeated use of gold-coated glass substrates and AFM tips [37,38].

\subsection{Formation of self-assembled structures}

For the deposition of SAMs, 1-undecanethiol $\left(\mathrm{CH}_{3}\left(\mathrm{CH}_{2}\right)_{10} \mathrm{SH}\right.$, 98\%), 11-mercapto-1-undecanol $\left(\mathrm{HS}\left(\mathrm{CH}_{2}\right)_{11} \mathrm{OH}, 97 \%\right), 11-$ mercaptoundecanoic acid $\left(\mathrm{HS}\left(\mathrm{CH}_{2}\right)_{10} \mathrm{CO}_{2} \mathrm{H}, 95 \%\right)$ (Sigma-Aldrich, Poole, UK; respectively referred to as ' $\mathrm{CH}_{3}$ ', ' $\mathrm{OH}$ ', and ' $\mathrm{CO}_{2} \mathrm{H}$ ') and 3,3,4,4,5,5,6,6,7,7,8,8,9,9,10,10,10-heptadecafluoro-1-decanethiol $\left(\mathrm{CF}_{3}\left(\mathrm{CF}_{2}\right)_{7}\left(\mathrm{CH}_{2}\right)_{2} \mathrm{SH}, \geq 99.0 \%\right.$; Fluka, USA; ' $\mathrm{CF}_{3}$ ') were separately dissolved in ethanol $\left(25 \mathrm{~cm}^{3} ; 1 \mathrm{mmol} \mathrm{dm}^{-3}\right)$. Gold-coated AFM probes NPG-20 'C' and gold-coated glass substrates were immersed for $16 \mathrm{~h}$ in the required parent-thiol solution. Prior to AFM experiments, freshly prepared SAMs were rinsed (ethanol) and dried (nitrogen). An uncoated gold surface was used as control.

\subsection{Polymer deposition}

For polymer coating, HEMA ( $\geq 99 \%$; Sigma-Aldrich, Poole, UK), DMAEMA (98\%; Sigma-Aldrich) and PFAC8 (97\%; Flurochem, Derbyshire, UK) were used as received. Cleaned, gold-coated AFM tips (NPG-20 'A') and gold-coated glass substrates were placed in a custom-built (dstl, Porton Down) inductively coupled glass cylindrical glow discharge reactor (diameter $10 \mathrm{~cm}$, volume $4.3 \times 10^{-3} \mathrm{~m}^{3}$; housed in a thermostatted Perspex cabinet; samples in glass dish located centrally). The reactor was connected (grease-free components) to an air-inlet stopcock, a thermocouple pressure gauge, a solid $\mathrm{CO}_{2}$-acetone cold trap and a two-stage rotary vacuum pump (Edwards). Prior to each coating procedure, the plasma reactor was cleaned with an air plasma (base pressure $<1 \times 10^{-2}$ mbar; $30 \mathrm{~min}$; $50 \mathrm{~W}$ at $13.56 \mathrm{MHz}$, an $\mathrm{L}-\mathrm{C}$ matching unit was used to minimise the standing wave ratio of the transmitted power between the radio frequency (RF) generator and the electrical discharge). Air was admitted to atmospheric pressure to allow the insertion of samples then the reactor was re-evacuated. Each monomer (ca. $20 \mathrm{mg}$ ), contained in a tube connected via a greaseless stopcock to the air-inlet, was subjected to several freeze-thaw cycles before vapour at a pressure of $0.1 \mathrm{mbar}$ was allowed to pass through the reactor (at room temperature for HEMA and DMAEA, at $34^{\circ} \mathrm{C}$ for PFAC8). After purging the reactor $(>2 \mathrm{~min}$ ) the plasma was ignited. To promote adhesion between the polymer and the substrate, the discharge was operated in continuous wave mode for $30 \mathrm{~s}$ followed by pulsed mode for a further $5 \mathrm{~min}$. The timing for pulsed-plasma polymer deposition commenced when a stable pulse envelope was displayed on the oscilloscope. The peak power of $40 \mathrm{~W}$ for pulses of duration $40 \mu \mathrm{s}$ at intervals of $20 \mathrm{~ms}$ corresponded with an average power input of $0.08 \mathrm{~W}$. Following plasma film deposition (0.03-7.5 $\mu$ g depending on area), the monomer vapour was allowed to purge through the reactor for a further $2 \mathrm{~min}$ before evacuation followed by admission of air and removal of the samples.

\subsection{Contact angle goniometry}

For CAG, filtered water ('FW'; all in $\mathrm{mJ} \mathrm{m} \mathrm{m}^{-2}: \gamma_{l}=72.8$, $\gamma_{l}^{L W}=21.8, \gamma_{l}^{+}=25.5$ and $\gamma_{l}^{-}=25.5$ ), 1,2-ethanediol ('EG', 99.8\%, Sigma-Aldrich, Poole, UK; all in $\mathrm{mJ} \mathrm{m}^{-2}: \gamma_{l}=48, \gamma_{l}{ }^{L W}=29, \gamma_{l}^{+}=1.92$ and $\gamma_{l}^{-}=47$ ) and diiodomethane ('DIM', >99\%, Sigma-Aldrich, Poole, UK; all in $\mathrm{mJ} \mathrm{m}^{-2}: \gamma_{l}=50.8, \gamma_{l}{ }^{L W}=50.8, \gamma_{l}^{+}=0$ and $\gamma_{l}^{-}=0$ ) were used. Advancing $\left(\theta_{A}\right)$ and receding $\left(\theta_{R}\right)$ contact angles of small drops $(1-5 \mu \mathrm{l})$ at $20^{\circ} \mathrm{C}$ (thermostated cell) were measured using a 
Table 1

Measured values of tip radius $R$, cantilever thickness $t$, length $l$, width $w$ and calculated values of $k$ for each cantilever used (Effective Young's modulus $E=175 \mathrm{GPa}$, density $\rho=3000 \mathrm{~kg} \mathrm{~m}^{-3}$ ).

\begin{tabular}{lclllll}
\hline $\begin{array}{l}\text { Tip } \\
\mathrm{SD}\end{array}$ & $\begin{array}{c}R / \mathrm{nm} \\
\pm 1\end{array}$ & $\begin{array}{l}l / \mu \mathrm{m} \\
\pm 0.1\end{array}$ & $\begin{array}{l}w / \mu \mathrm{m} \\
\pm 0.1\end{array}$ & $\begin{array}{l}t / \mu \mathrm{m} \\
\pm 0.02\end{array}$ & $\begin{array}{l}v / \mathrm{kHz} \\
\pm 0.5\end{array}$ & $\begin{array}{l}k / \mathrm{N} \mathrm{m}^{-1} \\
\pm 0.02\end{array}$ \\
\hline $\mathrm{Au}$ & 87 & 116.0 & 19.9 & 0.63 & 42.8 & 0.24 \\
$\mathrm{CO}_{2} \mathrm{H}$ & 64 & 119.5 & 20.6 & 0.52 & 58.8 & 0.22 \\
$\mathrm{OH}$ & 88 & 117.4 & 17.8 & 0.68 & 43.2 & 0.26 \\
$\mathrm{CH}_{3}$ & 64 & 113.3 & 17.2 & 0.69 & 55.4 & 0.29 \\
$\mathrm{CF}_{3}$ & 72 & 120.1 & 17.2 & 0.68 & 49.4 & 0.23 \\
$\mathrm{H}$ & 108 & 106.9 & 24.9 & 0.58 & 45.7 & 0.34 \\
$\mathrm{D} 1$ & 91 & 106.9 & 24.9 & 0.60 & 44.6 & 0.38 \\
$\mathrm{D} 2$ & 73 & 102.9 & 25.3 & 0.58 & 46.2 & 0.39 \\
$\mathrm{P} 1$ & 107 & 104.8 & 23.9 & 0.58 & 44.9 & 0.35 \\
$\mathrm{P} 2$ & 97 & 105.8 & 25.9 & 0.57 & 43.2 & 0.35 \\
$\mathrm{P} 3$ & 109 & 104.8 & 23.9 & 0.59 & 43.9 & 0.37 \\
\hline
\end{tabular}

Kruss G10 goniometer (Kruss GmbH, Germany). Values of $\theta_{A}$ were recorded at approximately $15 \mathrm{~s}$ after drop-surface contact, while $\theta_{R}$ was obtained by allowing the liquid drop to evaporate, or by withdrawing liquid from the drop, until its surface contact diameter began to decrease. Some dynamic contact angle measurements were also made using the Wilhelmy plate method [12]. A glass slide coated on both sides was suspended from the microbalance (Cahn model DCA322) while a beaker containing the probe liquid was moved vertically $\left(154 \mu \mathrm{m} \mathrm{s}^{-1}\right)$ over the substrate by a motorised stage.

\subsection{Atomic force microscopy}

AFM experiments were performed at ambient temperature, in air or under dry nitrogen, using a MultiMode/NanoScope IV Scanning Probe Microscope (Digital Instruments, Santa Barbara, CA, USA; Veeco software Version 6.11r1). The " $F$ vs. $x$ " curves were obtained using ' $C$ ' and ' $A$ ' V-shaped cantilevers with constant laser alignment (deflection sensitivity $=58 \pm 9 \mathrm{~nm} \mathrm{~V}^{-1}$ and $66 \pm 9 \mathrm{~nm} \mathrm{~V}^{-1}$ for thiol-functionalised and polymer-coated tips, respectively). After coating, the tip radius $(R)$ of each AFM tip was determined by scanning in contact mode (scan size $4 \mu \mathrm{m}$, scan rate $1.03 \mathrm{~Hz}$ ) an etched silicon surface that possessed features that were sharper than the tip curvature (TGT01; MikroMasch, San Jose, CA, USA). The radius of curvature was determined by drawing a line-profile across a tip artefact and exporting the height vs. width data into a Visual Basic program (University of Portsmouth) that allowed the manual fitting of a circle to the tip shape. Individual values of $k$ (Eq. (7) [39]) were obtained from measurements by scanning electron microscopy (JSM-6060LV, JEOL Ltd., Japan; 10 and $25 \mathrm{keV}$, $35 \mu \mathrm{m}$ spot-size, working distance $12-14 \mathrm{~mm}$ ) of the thickness $t$, length $l$ and width $w$ of the cantilever (Effective Young's modulus $E=175 \mathrm{GPa}$ [40]), Table 1 .

$k=\frac{E t^{3} w}{2 l^{3}}$

Measurements of $F_{a d}$ between tips and SAM-functionalised substrates or polymers were obtained in air (temperature, $T=22{ }^{\circ} \mathrm{C}$; relative humidity, $R H=36 \%$ ); the effect of humidity on adhesion was investigated over the $R H$ range $30-60 \%$. For each surface, " $F v s$. $x$ " curves $(10 \times 10$ force measurements; lateral separation $100 \pm 5 \mathrm{~nm}$; vertical displacement $800 \mathrm{~nm}$; scan rate, $1.03 \mathrm{~Hz}$ ) were obtained from each of ten areas $(1000 \mathrm{~nm} \times 1000 \mathrm{~nm}$, separated by $1000 \mathrm{~nm}$ ) on each surface. Measurements were repeated three times using SAM surfaces that had been formed sequentially on the same gold-coated glass substrate. An in-house Visual Basic program was used to extract values of $F_{a d}$ from the force curves. These data, in combination with the determined values for $k$ and $R$, allowed the evaluation of $W_{a d}$ and $\gamma_{T M}$ using Eqs. (5) and (6). The roughness $\left(R_{a}\right)$ of each substrate was determined by using a digital levelling algorithm (Veeco Image Analysis software V 7.10) to analyse surface scanning data (contact mode, NPG-20 'C' cantilever; 2 areas on 2 reformed surfaces, scan size $=5 \mu \mathrm{m}$, scan rate $=1 \mathrm{~Hz}$ ).

\subsection{X-ray photoelectron spectroscopy}

X-ray photoelectron spectroscopy (XPS) was carried out using a Kratos Axis ULTRA 'DLD' instrument employing a monochromatic Al-K $\alpha$ X-ray source ( $1486.6 \mathrm{eV}$ ) and operating at a power of $150 \mathrm{~W}$ with a pass energy of $20 \mathrm{eV}$.

\section{Results and discussion}

\subsection{Self-assembled structures}

The chemically specific intermolecular forces operating in air between the AFM tip and the probed substrate are susceptible to interferences from capillary water columns that may form between the tip and the substrate and also from the effects of correspondingly localised static electrical charges [41-43]. The latter are eliminated by the use of conducting, Au, substrates. The capillary condensation of water depends on $R H$ and on the surfaces. From previous reports, it was not observed between a tip and wafer both of silicon at $R H<60 \%$ [44], but did occur at $R H>40 \%$ [45] or $30 \%$ [46] when hydrophilic surfaces were involved. For two of the systems employed here, $F_{a d}$ was measured at $R H 0.1 \%$ and at $R H$ 36\%, Table 2. Since there is no significant difference between results at the two humidity levels, the capillary effects of condensed water will have been negligible. This is in accord with expectation since, under ambient conditions, the high energy surface of pure gold is known to become instantaneously coated through the adsorption of atmospheric organic contaminants, which alter the hydrophilicity of the surface. For a hydrophobic/hydrophobic or hydrophobic/hydrophilic system, the contributions from capillary forces are expected to be negligible irrespective of atmospheric humidity. For hydrophilic/hydrophilic systems, corresponding contributions become significant above certain humidity levels: the magnitude of the interaction depends critically on the precise tip shape at the last few nanometres of the tip apex, as is exemplified by the work of Gojzewski et al. [47]. Humidity did not appear to influence the measurements presented in this work.

For measurements of $F_{a d}$ between similar tips and surfaces, Table 3 , it is notable that the variability at individual surface locations $(n=100, \mathrm{SD}<0.95 \mathrm{nN}, \mathrm{CV}=0.1-6 \%)$ was much less than that between the ten locations on each sample $(\mathrm{SD}=1.8-3.3 \mathrm{nN}$,

Table 2

Effect of relative humidity of $F_{a d}$ ( 10 areas, $10 \times 10$ force measurements for each).

\begin{tabular}{|c|c|c|c|c|c|c|}
\hline \multirow[t]{3}{*}{ System } & \multicolumn{6}{|c|}{ Force-of-adhesion, $F_{a d} / \mathrm{nN}$} \\
\hline & \multicolumn{3}{|c|}{ In air $\left(R H=36 \%, T=22^{\circ} \mathrm{C}\right)$} & \multicolumn{3}{|c|}{ In dry $\mathrm{N}_{2}\left(R H=0.1 \%, T=24^{\circ} \mathrm{C}\right)$} \\
\hline & Range of $F_{a d}$ & Range of SD & Overall $F_{a d} \pm$ SD & Range of $F_{a d}$ & Range of SD & Overall $F_{a d} \pm \mathrm{SD}$ \\
\hline$A u_{\text {surface }}-A u_{\text {tip }}$ & $49-59$ & $0.03-1.01$ & $54 \pm 3$ & $46-57$ & $0.09-1.12$ & $52 \pm 5$ \\
\hline $\mathrm{OH}_{\text {surface }}-\mathrm{Au}_{\text {tip }}$ & $42-49$ & $0.08-0.74$ & $46 \pm 4$ & $39-52$ & $0.22-1.72$ & $45 \pm 7$ \\
\hline
\end{tabular}


Table 3

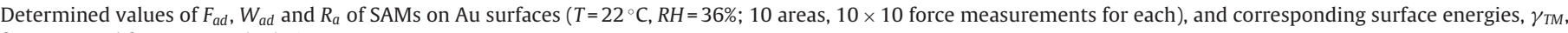
from JKR and from DMT calculations.

\begin{tabular}{|c|c|c|c|c|c|c|}
\hline System & $F_{a d} / \mathrm{nN}$ & $R_{a} / \mathrm{nm}$ & $W_{a d}(\mathrm{JKR}) / \mathrm{mJ} \mathrm{m}^{-2}$ & $W_{a d}(\mathrm{DMT}) / \mathrm{mJ} \mathrm{m}^{-2}$ & $\gamma_{T M}(\mathrm{JKR}) / \mathrm{mJ} \mathrm{m}^{-2}$ & $\gamma_{T M}(\mathrm{DMT}) / \mathrm{mJ} \mathrm{m}^{-2}$ \\
\hline $\mathrm{Au}-\mathrm{Au}$ & $54 \pm 3$ & $3.4 \pm 0.2$ & $131 \pm 8$ & $98 \pm 6$ & $65 \pm 2$ & $49 \pm 2$ \\
\hline $\mathrm{OH}-\mathrm{OH}$ & $30 \pm 2$ & $3.6 \pm 0.3$ & $99 \pm 6$ & $74 \pm 5$ & $49 \pm 3$ & $37 \pm 2$ \\
\hline $\mathrm{CO}_{2} \mathrm{H}-\mathrm{CO}_{2} \mathrm{H}$ & $36 \pm 3$ & $2.4 \pm 0.3$ & $87 \pm 6$ & $65 \pm 5$ & $44 \pm 4$ & $33 \pm 2$ \\
\hline $\mathrm{CH}_{3}-\mathrm{CH}_{3}$ & $19 \pm 2$ & $3.5 \pm 0.2$ & $63 \pm 8$ & $47 \pm 6$ & $32 \pm 3$ & $24 \pm 3$ \\
\hline $\mathrm{CF}_{3}-\mathrm{CF}_{3}$ & $10 \pm 1$ & $2.2 \pm 0.2$ & $30 \pm 4$ & $22 \pm 3$ & $15 \pm 2$ & $11 \pm 2$ \\
\hline
\end{tabular}

Table 4

Surface energies $\left(\gamma_{s}\right)$ as calculated from the mean values of advancing and receding contact angles on SAMs $\left(n=8\right.$; $\left.20^{\circ} \mathrm{C}\right)$; individual data for gold are also presented.

\begin{tabular}{|c|c|c|c|c|c|}
\hline Surface & $\gamma_{s}^{+} / \mathrm{mJ} \mathrm{m}^{-2}$ & $\gamma_{s}^{-} / \mathrm{mJ} \mathrm{m}^{-2}$ & $\gamma_{s}^{L W} / \mathrm{mJ} \mathrm{m}^{-2}$ & $\gamma_{s} / \mathrm{mJ} \mathrm{m}^{-2}$ & $\gamma_{s} / \mathrm{mJ} \mathrm{m}^{-2}$ (Refs. $\left.[46,49,50]\right)$ \\
\hline Au (low) & 6.2 & 0.6 & 40.1 & $40 \pm 1$ & - \\
\hline Au (high) & 2.2 & 77.1 & 42.2 & $64 \pm 1$ & - \\
\hline $\mathrm{OH}$ & 6.5 & 46.5 & 40.3 & $44 \pm 3$ & 52.9 \\
\hline $\mathrm{CO}_{2} \mathrm{H}$ & 6.6 & 44.0 & 39.7 & $41 \pm 3$ & 39.3 \\
\hline $\mathrm{CH}_{3}$ & 0.6 & 5.0 & 25.6 & $26 \pm 2$ & $21 \pm 1 ; 27.2$ \\
\hline $\mathrm{CF}_{3}$ & 0.1 & 0.8 & 13.9 & $15 \pm 2$ & $15.0 \pm 0.4$ \\
\hline
\end{tabular}

$\mathrm{CV}=6-15 \%)$. Further, the values for $F_{a d}$ and $W_{a d}$ correlated with the expected capability of each SAM/tip combination to participate in van der Waals' interactions and to share electron pairs: $\mathrm{OH}>\mathrm{CO}_{2} \mathrm{H}>\mathrm{CH}_{3}>\mathrm{CF}_{3}$. In all cases, $R_{a}$ values for SAMs were similar to or slightly less than those for the underlying gold substrates. Thus the deposition of $\mathrm{CO}_{2} \mathrm{H}$ and $\mathrm{CF}_{3}$ SAMs had a slight surfacesmoothing effect. Surface roughness, which is associated with variations in the area of interaction between the tip and the substrate, may account for a significant proportion of the variability in the determined values for $F_{a d}$ and $W_{a d}$. The influence of experimental protocol may be appreciated by comparing the $W_{a d}$ values for the interacting $\mathrm{OH}-\mathrm{OH}$ and $\mathrm{CH}_{3}-\mathrm{CH}_{3}$ surfaces (Table 3) with previously published data: $W_{a d}$ (DMT, Au-coated Si wafer surfaces, Au-coated tips): $109.2-176.7$ and $43.7-73.0 \mathrm{~mJ} \mathrm{~m}^{-2}$, respectively, $R H=15 \%$ [48] and $78 \pm 5$ and $17 \pm 3 \mathrm{~mJ} \mathrm{~m}^{-2}$ [25], respectively. Given the radii of the tips used (Table 1 ), the surface resolution of $c a$. $100 \mathrm{~nm}$ was the best that could be achieved.

Liquid-solid contact angles on gold displayed contrasting behaviour, with FW showing a much greater hysteresis than either DIM or EG. The values for FW of $\theta_{A}\left(81.5 \pm 2^{\circ}\right)$ and $\theta_{R}\left(29.1 \pm 0.9^{\circ}\right)$ correspond with the previously reported upper [48] and lower [49] limits and mainly reflect surface heterogeneity. For DIM, the hysteresis of $6^{\circ}$ is attributed to surface roughness.

For all three probe liquids on all of the SAM surfaces, the value of contact angle hysteresis $\left(4-8^{\circ}\right)$ was close to that for DIM on uncoated $\mathrm{Au}$, again indicating that the deposited SAMs followed the topography of the Au substrates. Similar previous results (hysteresis $5^{\circ}$ for perfluorinated alkanethiols deposited on gold) were attributed to stable chemisorbed films [50]. To within the error

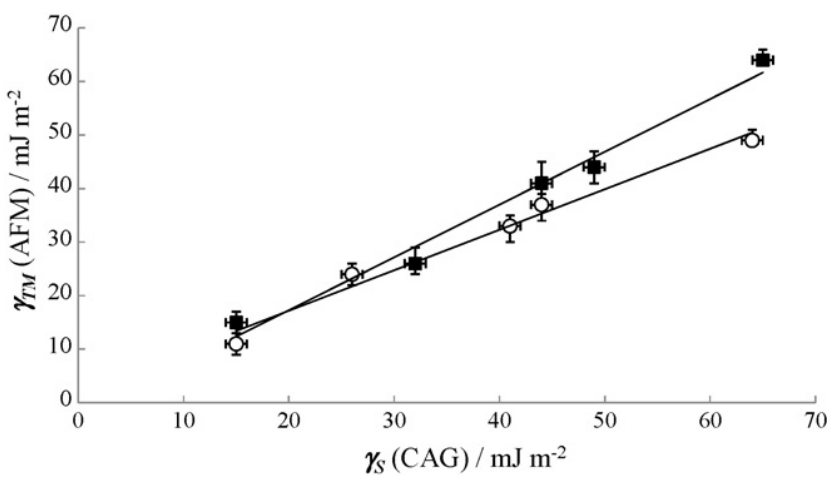

Fig. 1. Surface energies determined by CAG (mean $\theta$ values) $v$ s. those from AFM (JKR or DMT methods; $n=3)$ : ( $)$ CAG vs. JKR $\left(R^{2}=0.9815\right)$, ( $\left.\bigcirc\right)$ CAG vs. DMT $\left(R^{2}=0.9805\right)$. associated with standard deviations in contact angles of $\mathrm{ca} .3^{\circ}$, the surface energies of the SAMs have been evaluated using mean contact angles (Table 4). For the thiol-functionalised substrates, the surface energy and related components obtained from CAG decreased in the order $\mathrm{OH}>\mathrm{CO}_{2} \mathrm{H}>\mathrm{CH}_{3}>\mathrm{CF}_{3}$ (Table 4), following the trend shown by values of $F_{a d}$ (Table 3 ). Except for $\mathrm{OH}, \gamma_{s}$ values from CAG are in agreement (within error limits) with those reported in the literature $[48,50-52]$.

Since each AFM tip - substrate pair was coated with the same SAM, $\gamma_{T M}\left(=\gamma_{S M}\right)$ was calculated from $W_{a d}$ (Eq. (6), Table 3). For Au (high energy component) and for SAMs terminated with $-\mathrm{CO}_{2} \mathrm{H}$, $-\mathrm{OH}$ and $-\mathrm{CF}_{3}$, the $\gamma_{T M}$ values from AFM (JKR) are in agreement (within the range of the SDs) with surface energies $\left(\gamma_{s}\right)$ obtained from CAG (Table 4; Fig. 1). The $\mathrm{CH}_{3}$-terminated SAM exhibits a somewhat anomalous behaviour [38] in that it is the application of the DMT method that yields $\gamma_{T M}$ values that are in good agreement with $\gamma_{s}$; values of $\gamma_{T M}$ (JKR) are at the extreme limits of experimental error. These findings indicate the validity of the described AFM technique as a means of determining surface energy, and identify the JKR approach as that which yields surface energy data that correspond with those quoted conventionally from contact angle work.

\subsection{Polymer surfaces}

To assess the applicability of the AFM technique to the determination of the surface energy of materials other than SAMs, $F_{a d}$ values

Table 5

$\mathrm{C}(1 \mathrm{~s})$ Binding energies and atomic percentages of elements at the surface of polymer-film structures, as determined by XPS.

\begin{tabular}{lllll}
\hline Polymer & Assignment & Binding energy/eV & Experimental \% & Theoretical \% \\
\hline HEMA & $\mathrm{CH}_{x}$ & 285.0 & $31.5 \pm 0.5$ & 33.3 \\
& $\mathrm{C}-\mathrm{C}=\mathrm{O}$ & 285.7 & $15.8 \pm 3.2$ & 16.7 \\
& $\underline{\mathrm{C}}-\mathrm{OH}$ & 286.8 & $36.4 \pm 3.1$ & 33.3 \\
& $\underline{\mathrm{C}}-\mathrm{O}(\mathrm{O})$ & 289.2 & $16.2 \pm 0.2$ & 16.7 \\
DMAEMA & $\underline{\mathrm{C}} \mathrm{H}_{x}$ & 285.0 & $25.9 \pm 0.5$ & 25.0 \\
& $\underline{\mathrm{C}}-\mathrm{C}=\mathrm{O} / \underline{\mathrm{C}}-\mathrm{N}$ & 285.7 & $42.8 \pm 1.5$ & 50.0 \\
& $\underline{\mathrm{C}}-\mathrm{O}$ & 286.8 & $17.5 \pm 1.0$ & 12.5 \\
& $\underline{\mathrm{C}}-\mathrm{O}(\mathrm{O})$ & 289.0 & $13.9 \pm 0.1$ & 12.5 \\
PFAC8 & $\underline{\mathrm{C}} \mathrm{H}_{x}$ & 284.6 & $7.3 \pm 1.7$ & 7.7 \\
& $\underline{\mathrm{C}}-\mathrm{C}=\mathrm{O}$ & 285.7 & $14.4 \pm 1.6$ & 15.4 \\
& $\underline{\mathrm{C}} \mathrm{H}_{2}-\mathrm{O}$ & 286.6 & $8.2 \pm 1.6$ & 7.7 \\
& $\mathrm{O}-\mathrm{C}=\mathrm{O}$ & 288.2 & $7.3 \pm 0.3$ & 7.7 \\
& $\mathrm{CF}_{2}$ & 290.6 & $52.6 \pm 0.6$ & 53.4 \\
& $\underline{\mathrm{C}}_{3}$ & 292.7 & $8.5 \pm 0.7$ & 7.7 \\
\hline
\end{tabular}


Table 6

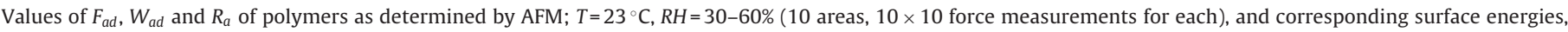
$\gamma_{T M}$, from JKR and from DMT calculations.

\begin{tabular}{|c|c|c|c|c|c|c|c|c|c|}
\hline System & Tip no. & $\% R H$ & Time/week no. & $F_{a d} / \mathrm{nN}$ & $R_{a} / \mathrm{nm}$ & $W_{a d}(\mathrm{JKR}) / \mathrm{mJ} \mathrm{m}^{-2}$ & $W_{a d}(\mathrm{DMT}) / \mathrm{mJ} \mathrm{m}^{-2}$ & $\gamma_{T M}(\mathrm{JKR}) / \mathrm{mJ} \mathrm{m}^{-2}$ & $\gamma_{T M}(\mathrm{DMT}) / \mathrm{mJ} \mathrm{m}^{-2}$ \\
\hline \multirow{3}{*}{ HEMA-HEMA } & 1 & 60 & 0 & $13 \pm 3$ & \multirow{3}{*}{0.93} & $26 \pm 6$ & $20 \pm 4$ & $13 \pm 3$ & $10 \pm 2$ \\
\hline & 1 & 36 & 1 & $16 \pm 1$ & & $32 \pm 3$ & $24 \pm 2$ & $16 \pm 1$ & $12 \pm 1$ \\
\hline & 1 & 30 & 12 & $42 \pm 1$ & & $96 \pm 2$ & $72 \pm 2$ & $48 \pm 1$ & $36 \pm 1$ \\
\hline \multirow{4}{*}{ DMAEMA-DMAEMA } & 2 & 56 & 0 & $14 \pm 1$ & \multirow{4}{*}{2.12} & $40 \pm 2$ & $30 \pm 2$ & $20 \pm 1$ & $15 \pm 1$ \\
\hline & 2 & 42 & 0 & $18 \pm 2$ & & $52 \pm 5$ & $39 \pm 4$ & $26 \pm 3$ & $20 \pm 2$ \\
\hline & 1 & 35 & 1 & $40 \pm 2$ & & $94 \pm 4$ & $70 \pm 3$ & $47 \pm 2$ & $35 \pm 2$ \\
\hline & 2 & 30 & 12 & $36 \pm 2$ & & $106 \pm 4$ & $79 \pm 4$ & $53 \pm 3$ & $40 \pm 2$ \\
\hline \multirow{5}{*}{ PFAC8-PFAC8 } & 2 & 57 & 0 & $28 \pm 4$ & \multirow{5}{*}{2.27} & $61 \pm 9$ & $46 \pm 7$ & $30 \pm 4$ & $23 \pm 3$ \\
\hline & 2 & 40 & 0 & $19 \pm 3$ & & $42 \pm 7$ & $32 \pm 5$ & $21 \pm 3$ & $16 \pm 3$ \\
\hline & 2 & 35 & 1 & $22 \pm 3$ & & $44 \pm 5$ & $33 \pm 4$ & $22 \pm 3$ & $17 \pm 2$ \\
\hline & 1 & 35 & 1 & $22 \pm 1$ & & $43 \pm 3$ & $32 \pm 2$ & $21 \pm 1$ & $16 \pm 1$ \\
\hline & 2 & 30 & 12 & $24 \pm 1$ & & $53 \pm 2$ & $40 \pm 2$ & $27 \pm 1$ & $20 \pm 1$ \\
\hline
\end{tabular}

have been obtained for interactions involving polymer-coated tips and substrates. XPS experiments showed that the composition of the polymeric coating was close to that expected on the basis of precursor-monomer composition, and that the deposited polymers did not exhibit any significant chain-orientation effects (Fig. 1, Table 5). The coating process increased the radius of the tip by ca. $20 \mathrm{~nm}$ (Table 1 ) and the average roughness of polymer-coated substrates $\left(R_{a}<3 \mathrm{~nm}\right.$, Table 6$)$ was very similar to that of the SAMs. Standard deviations on measurements of $F_{a d}$ were slightly lower for polymer surfaces than for SAMs, perhaps because the slightly enlarged tip reduced the influence of surface undulations; there was no indication of variation with surface location. The similarity between the chemical functionalisation of the pendant groups in PFAC8 and that of the $\mathrm{CF}_{3}$ SAM has also provided a valuable comparator. For immediate measurements at ambient humidity, $\gamma_{T M}$ for PCFC8, calculated using DMT $\left(16 \mathrm{~mJ} \mathrm{~m}^{-2}\right)$, corresponded closely with that for the $\mathrm{CF}_{3} \mathrm{SAM}\left(15 \mathrm{~mJ} \mathrm{~m}^{-2}\right)$ but $\gamma_{s}$ for PCFC8 from CAG (advancing angles) was significantly lower $\left(8 \mathrm{~mJ} \mathrm{~m}^{-2}\right)$. Very low surface energies for fluorinated polymers have been observed previously $[53,54]$ and are associated with unusually large contact angles for both water and DIM. The appreciable hysteresis observed for PCFC8 indicated a heterogeneous surface containing domains with a much higher surface energy. If the individual surface domains were much smaller than the diameter of the AFM tip, then measurements of $F_{a d}$ would give intermediate values of $\gamma_{T M}$ as observed.

In a study of the effects of humidity and the age of the polymer film, $F_{a d}$ was monitored over a 12 -week period for samples that had been stored at controlled RH (Table 6). For HEMA-HEMA or DMAEMA-DMAEMA interactions, at early stages ( 0 -1 week) values of $F_{a d}$ (and hence also $W_{a d}$ and $\gamma_{T M}$ ) were not greatly affected by humidity $(R H \leq 60 \%)$, Table 6 . After 12 weeks at ambient humidity ( $R H 30 \%$ ), however, both interactions increased by $>100 \%$, probably reflecting the absorption of water by the hydrophilic materials. It is notable that the surface energies determined by CAG (receding angles; Table 7) are close to values of $\gamma_{T M}$ (JKR) for the samples exposed to water vapour: sorption of water may have been more rapid during CAG measurements (saturated vapour and absorption from liquid drops). The observations also indicate that the JKR

\section{Table 7}

Surface energies $\left(\gamma_{s}\right)$ as calculated from advancing and from receding average contact angles on polymers films $\left(n=8 ; 20^{\circ} \mathrm{C}\right)$.

\begin{tabular}{lcl}
\hline Surface & $\gamma_{s}(\mathrm{CAG}$, advancing $) / \mathrm{mJ} \mathrm{m}^{-2}$ & $\gamma_{s}(\mathrm{CAG}$, receding $) / \mathrm{mJ} \mathrm{m}^{-2}$ \\
\hline HEMA & $42 \pm 2$ & $43 \pm 1$ \\
DMAEMA & $43 \pm 3$ & $47 \pm 3$ \\
PFAC8 $^{\mathrm{a}}$ & $8 \pm 2$ & $30 \pm 3$ \\
\hline
\end{tabular}

a Values obtained using the Owens-Wendt two-liquid method [10]. calculation is more reliable for AFM tips with all three coatings. For PFAC8, despite its relative incompatibility with water, $\gamma_{T M}$ was increased considerably by exposure to high humidity, and was also increased by prolonged exposure to ambient humidity.

\section{Conclusions}

The AFM method for acquiring surface energy data has been tested using SAMs with terminal functionalities of $-\mathrm{OH}$, $-\mathrm{CO}_{2} \mathrm{H},-\mathrm{CH}_{3}$ and $-\mathrm{CF}_{3}$, and also with films of substituted poly(methacrylate)s. Values of $\gamma_{T M}$ determined under ambient conditions have been found to be consistent with those of $\gamma_{s}$ obtained conventionally from CAG. The complementarities of the techniques have been shown: for surfaces that are heterogeneous, AFM gives average total surface energies at each point probed (lateral resolution of $c a .100 \mathrm{~nm}$ ) while CAG yields surface-averaged energies of high and low energy domains in heterogeneous surfaces and resolves the contributions of individual surface energy components.

\section{Acknowledgement}

We thank the Institute of Biomedical and Biomolecular Sciences (IBBS), University of Portsmouth for providing a studentship to DL.

\section{References}

[1] J.C. Hooton, C.S. German, M. Davies, C.J. Roberts, Eur. J. Pharm. Sci. 28 (2006) 315-324.

[2] J. Pacifico, K. Endo, S. Morgan, P. Mulvaney, Langmuir 22 (2006) 11072-11076

[3] W.M. Merrill, A.V. Pocius, B.V. Thakker, M. Tirrell, Langmuir 7 (1991) 1975-1980.

[4] A. Amirfazli, A. Neumann, Adv. Colloid Interface Sci. 110 (2004) 121-141.

[5] T. Blake, J. Colloid Interface Sci. 299 (2006) 1-13.

[6] A. Gajewski, Int. J. Heat Mass Transfer 48 (2005) 4829-4834.

[7] W. Zisman, Adv. Chem. Ser. 43 (1963) 1-13.

[8] J. Long, M. Hyder, R. Huang, P. Chen, Adv. Colloid Interface Sci. 118 (2005) 173-190.

[9] R.G. Good, C.J. van Oss C, in: M.E. Schrader, G. Loeb (Eds.), Modern Approaches to Wettability: Theory and Applications, Plenum Press, New York, 1991, pp. $1-27$.

[10] D.K. Owens, R.C.J. Wendt, J. Appl. Polym. Sci. 13 (1969) 1741-1747.

[11] J.D. Andrade, L.M. Smith, D.E. Gregoris, in: J.D. Andrade (Ed.), Surface and Interfacial Aspects of Biomedical Polymers, 1, Plenum Press, New York, 1985, pp. 249-289, Chapter 7.

[12] N.A. Burnham, A.J. Kulik, in: B. Bhushan (Ed.), Surface Forces and Adhesion Handbook of Micro/Nanotribology, CRC Press, Santa Clara, 1999, pp. 247-271.

[13] K.L. Johnson, K. Kendall, A.D. Roberts, Proc. R. Soc. Lond. A 324 (1971) 301-320

[14] B.V. Derjaguin, V.M. Muller, Yu.P. Toporov, J. Colloid Interface Sci. 53 (1975 314-326.

[15] J. Drelich, G.W. Tormoen, E.R. Beach, J. Colloid Interface Sci. 280 (2004) 484-497.

[16] J. Israelachvili, Intermolecular and Surface Forces, Academic Press, New York, 1992.

[17] M. Stone, T.G. Nevell, J. Tsibouklis, J. Mater. Lett. 37 (1998) 102-105.

[18] K. Benzarti, C. Perruchot, M.M. Chehimi, Colloids Surf. A: Physicochem. Eng. Aspects 286 (2006) 78-91. 
[19] P. Warszynski, G. Papastavrou, K. Wantke, H. Mohwald, Colloids Surf. A: Physicochem. Eng. Aspects 214 (2003) 61-75.

[20] O. Noel, M. Brogly, G. Castelein, J. Schultz, Eur. Polym. J. 40 (2004) 965-974.

[21] A. Noy, D.V. Vezenov, C.M. Lieber, Annu. Rev. Mater. Sci. 27 (1997) 381-421.

[22] A. Ulman, Chem. Rev. 96 (1996) 1533-1554.

[23] N.K. Chaki, M. Aslam, J. Sharma, K. Vijayamohanan, Proc. Indian Acad. Sci. 113 (2001) 659-670.

[24] M.K. Chaudhury, Mater. Sci. Eng. R16 (1996) 97-159.

[25] H. Awada, G. Castelein, M. Brogly, Surf. Interface Anal. 37 (2005) 755-764.

[26] J. Tsibouklis, T.G. Nevell, Adv. Mater. 15 (2003) 647-650.

[27] J. Singh, J.E. Whitten, J. Macromol. Sci. 45 (2008) 884-891.

[28] P.J. Eaton, J.R. Smith, P. Graham, J.D. Smart, T.G. Nevell, J. Tsibouklis, Langmuir 18 (2002) 3387-3389.

[29] E.R. Beach, G.W. Tormoen, J. Drelich, J. Adhes. Sci. Technol. 16 (2002) 845868.

[30] O. Noel, M. Brogly, G. Castelein, J. Schultz, Langmuir 20 (2004) 2707-2712.

[31] D.V. Vezenov, A. Noy, P. Ashby, J. Adhes. Sci. Technol. 19 (2005) 313-364.

[32] M. Brogly, O. Noel, H. Awada, G. Castelein, J. Schultz, C. R. Chim. 9 (2006) 99110.

[33] J.C. Hooton, C.S. German, M.C. Davies, C.J. Roberts, Eur. J. Pharm. Sci. 28 (2006) 315-324.

[34] J.F. Zhang, S. Ebbens, X. Chen, Z. Jin, S. Luk, C. Madden, N. Patel, C.J. Roberts, Pharm. Res. 23 (2006) 401-407.

[35] R. Brunner, I. Etsion, F.E. Talke, Rev. Sci. Instrum. 80 (2009), 055109/1-055109/5

[36] S.C. Clear, P.F. Nealey, J. Colloid Interface Sci. 213 (1999) 238-250.

[37] D.A. Lamprou, J.R. Smith, T.G. Nevell, E. Barbu, C.R. Willis, J. Tsibouklis, Appl. Surf. Sci. 256 (2010) 1961-1968.
[38] D.A. Lamprou, J.R. Smith, T.G. Nevell, E. Barbu, C. Stone, C.R. Willis, R.J. Ewen, J. Tsibouklis, Surface Sci. 604 (2010) 540-546.

[39] W.F. Stokey, Shock and Vibration Handbook, McGraw-Hill, New York, 1989.

[40] L.L. Hazel, V.V. Tsukruk, Thin Solid Films 339 (1999) 249-257.

[41] B. Cappella, P. Baschieri, C. Frediani, P. Miccoli, C. Ascoli, IEEE Eng. Med. Biol. 16 (1997) 58-65.

[42] S.L. Sedin, K.L. Rowlen, Anal. Chem. 72 (2000) 2183-2189.

[43] L. Chen, X. Gu, M.J. Fasolka, J.W. Martin, T. Nguyen, Langmuir 25 (2009) 3494-3503.

[44] A. Feiler, P. Jenkins, M.W. Rutland, J. Adhes. Sci. Technol. 19 (2005) 165179.

[45] J. Hu, X.D. Xiao, D.F. Ogletree, M. Salmeon, Surf. Sci. 344 (1995) 221236.

[46] O. Noel, H. Awada, G. Castelein, M. Brogly, J. Schultz, J. Adhes. 82 (2006) 649-669.

[47] H. Gojzewski, M. Kappl, A. Ptak, H.-J. Butt, Langmuir 26 (2010) 1837-1847.

[48] G.W. Tormoen, J. Drelich, E.R. Beach, J. Adhes. Sci. Technol. 18 (2004) 1-17.

[49] R.R. Sahoo, A. Patnaik, Appl. Surf. Sci. 245 (2004) 26-38.

[50] K. Tamada, J. Nagasawa, F. Nagahishi, K. Abe, M. Hara, W. Knoll, T. Ishida, H Fukushima, S. Miyashita, T. Usui, T. Koini, T.R. Lee, Thin Solid Films 150 (1998) 327-329.

[51] Y.F. Miura, M. Takenaga, T. Koini, M. Graupe, N. Garg, R.L. Graham, T.R. Lee, Langmuir 14 (1998) 5821-5825.

[52] K. Jing, P. Rowntree, Langmuir 23 (2007) 509-516.

[53] J. Tsibouklis, M. Stone, A.A. Thorpe, P. Graham, T.G. Nevell, R.J. Ewen, Langmuir 15 (1999) 7076-7079.

[54] J. Tsibouklis, P. Graham, P.J. Eaton, J.R. Smith, T.G. Nevell, J.D. Smart, R.J. Ewen, Macromolecules 33 (2000) 8460-8465. 